\title{
The syndrome of inappropriate antidiuretic hormone: current and future management options
}

\author{
Mark Sherlock and Chris J Thompson ${ }^{1}$ \\ Centre for Endocrinology, Diabetes and Metabolism, School of Clinical and Experimental Medicine, University of Birmingham, Birmingham, \\ B15 2TT, UK and ${ }^{1}$ Academic Department of Diabetes and Endocrinology, Beaumont Hospital and RCSI Medical School, Beaumont Road, Dublin 9, Ireland \\ (Correspondence should be addressed to C J Thompson; Email: christhompson@beaumont.ie)
}

\begin{abstract}
Hyponatraemia is the commonest electrolyte abnormality, and syndrome of inappropriate antidiuretic hormone (SIADH) is the most frequent underlying pathophysiology. Hyponatraemia is associated with significant morbidity and mortality, and as such appropriate treatment is essential. Treatment options for SIADH include fluid restriction, demeclocycline, urea, frusemide and saline infusion, all of which have their limitations. The introduction of the vasopressin-2 receptor antagonists has allowed clinicians to specifically target the underlying pathophysiology of SIADH. Initial studies have shown good efficacy and safety profiles in the treatment of mild to moderate hyponatraemia. However, studies assessing the efficacy and safety of these agents in acute severe symptomatic hyponatraemia are awaited. Furthermore, the cost of these agents at present may limit their use.
\end{abstract}

European Journal of Endocrinology 162 S13-S18

\section{Introduction}

The previous article in this supplement established that hyponatraemia due to syndrome of inappropriate antidiuretic hormone (SIADH) is associated with significant morbidity (1), mortality (2-5) and increased length of hospital stay (6). Symptoms are related primarily due to the severity of the hyponatraemia, though the speed of fall in plasma sodium concentration has a major influence on the plasma sodium concentration at which symptoms are noted (7); patients with a rapid fall in plasma sodium are far more likely to experience symptoms than patients with an equivalent level of hyponatraemia which has taken a long time to develop. In addition to symptoms, there is good evidence that patients are subject to serious sequelae of hyponatraemia, including gait abnormalities and falls (8) and increased fracture risk (9). As hyponatraemia is particularly common in the elderly, the latter two morbidities assume greater significance in this age group. With severe hyponatraemia (plasma sodium $<120 \mathrm{mmol} / \mathrm{l}$ ), there is an exponential increase in mortality, with death rates of $50 \%$ reported as plasma sodium concentration falls below $115 \mathrm{mmol} / \mathrm{l}(2)$.

The symptoms, sequelae and associated mortality therefore dictate that treatment for hyponatraemia due to SIADH is essential to promote patients wellbeing and to lessen the risk of serious complications. Accurate

This paper forms part of a supplementary issue of European Journal of Endocrinology. Otsuka Pharmaceutical Europe Ltd. has supported the publication of this supplement. diagnosis of SIADH and the differentiation from other causes of hyponatraemia is the first essential step in determining appropriate treatment. Diagnostic criteria for SIADH are included in Table 1 (10). In this article, we review the existing treatments available for the management of SIADH and discuss the potential impact of a new class of medications, the vasopressin receptor antagonists or vaptans.

\section{Who needs treatment?}

The traditional view is that only severe hyponatraemia (plasma sodium concentrations $<125 \mathrm{mmol} / \mathrm{l}$ ) requires intervention. The neurological sequelae of severe hyponatraemia, which are thought to reflect cerebral oedema, are well recognised, and range from mild headache, nausea and altered cognition to seizures and coma, as the severity of the hyponatraemia worsens, or if the fall in plasma sodium concentration is rapid. Acute falls in plasma sodium concentration can produce lifethreatening neurological complications, which may necessitate emergency treatment with hypertonic saline infusion. When a patient has symptoms of hyponatraemia, there is little doubt that active intervention is not simply desirable but essential.

In addition to the threat of neurological complications, hyponatraemia has implications for mortality and length of hospital stay. Gill and colleagues, in a prospective, case-controlled study, found that patients admitted to hospital with severe hyponatraemia (plasma sodium $<125 \mathrm{mmol} / \mathrm{l}$ ) had a higher hospital mortality when compared with normonatraemic admissions (2). 
Table 1 Diagnostic criteria for SIADH (10).

\section{Diagnostic criteria for SIADH}

Essential

- Plasma osmolality $<270$ mosmol $/ \mathrm{kg} \mathrm{H}_{2} \mathrm{O}$

- Inappropriate urinary concentration $\left(\mathrm{U}_{\mathrm{osm}}>100 \mathrm{mosmol} / \mathrm{kg} \mathrm{H}_{2} \mathrm{O}\right)$

- Patient is clinically euvolaemic

- Elevated urinary sodium (>40 mmol/l), with normal salt and water intake

- Exclude hypothyroidism and glucocorticoid deficiency

Supplemental

- Abnormal water load test, i.e. inability to excrete at least $90 \%$ of a $20 \mathrm{ml} / \mathrm{kg}$ water load in $4 \mathrm{~h}$ and/or failure to dilute urine to $\mathrm{U}_{\text {osm }}<100 \mathrm{mosmol} / \mathrm{kg} \mathrm{H}_{2} \mathrm{O}$

- Plasma AVP levels inappropriately elevated relative to plasma osmolality

Tests for supplemental criteria should only be performed in rare situations and in units with expertise in this area as they may aggravate hyponatraemia. Table reproduced with permission from Smith DM, McKenna K \& Thompson CJ. Hyponatremia. Clinical Endocrinology 200052 679-678.

Mortality was higher still if hyponatraemia developed during admission, as a result of illness or treatment. Mortality was predictably higher with more severe hyponatraemia. Interestingly, hyponatraemia was associated with greater length of hospital stay, a phenomenon also reported in a separate retrospective study of patients with hyponatraemia due to subarachnoid haemorrhage (6). Neither study was able to determine whether the hyponatraemia was causally associated with longer inpatient stay or simply a marker for more severe disease processes, which warranted prolonged admission per se.

Clayton and colleagues also reported greater mortality in patients with hyponatraemia, and in addition found that the excess mortality continued after discharge from hospital, though they were able to conclude that the high mortality reflected the severity of underlying disease processes, in particular congestive cardiac failure and cirrhosis (11). A smaller study from Holland showed important findings (12); when patients with hyponatraemia on admission were compared with those who developed hyponatraemia during hospital stay, there was a similar incidence of neurological symptoms in both the groups, but patients who developed hyponatraemia during admission had a longer duration of admission ( 31 vs 18 days). Crucially, the authors were able to demonstrate that patients who were not specifically treated for hyponatraemia during hospital admission had higher mortality rates (37 vs $13 \%$ ). This is the first data to show that inadequate treatment of hyponatraemia leads to worse outcomes. There is also clear data on the improvement in symptoms after treatment of hyponatraemia; in a study of 223 consecutive patients with thiazide-induced hyponatraemia, Chow et al. (13) were able to show complete resolution of symptoms (falls, dizziness, lethargy, confusion, headaches and seizures) when hyponatraemia resolved with discontinuation of diuretic therapy.
In contrast to the widespread acceptance that treatment of severe hyponatraemia is important, mild hyponatraemia has been regarded as asymptomatic, and treatment has been considered to be unnecessary. However, it is clear from recent data that mild hyponatraemia is not as benign a condition as previously thought. A recent matched case-control study of 122 patients with hyponatraemia due to SIADH or hypovolaemic hyponatraemia have shown that patients had four times increased likelihood of falls compared with 244 matched controls (adjusted odds ratio 67.4, P<0.01), a difference which was not explainable by an excess of acute illness or medication (8). The frequency of falls was similar in patients with mild hyponatraemia (plasma sodium 130-132 mmol/l, 19\%) when compared with severe hyponatraemia (plasma sodium concentration 115-117 mmol/l, 22\%). A subgroup of hyponatraemic patients underwent neurocognitive assessment; there were significant abnormalities of gait identified, which improved significantly after correction of hyponatraemia. In a separate study, patients with falls and fractures were more likely to have pre-existing hyponatraemia than patients with falls alone, with even mild hyponatraemia (plasma sodium $131 \pm 3 \mathrm{mmol} / \mathrm{l}$ ) associated with an increased fracture risk in elderly patients (9). Data from rodent studies have shown bone demineralisation in hyponatraemic compared with normonatraemic animals, which raise the intriguing possibility that hyponatraemia may predispose to fractures not just by causing gait abnormalities and falls but also by predisposing to osteoporosis (14).

The weight of existing data provides compelling evidence that hyponatraemia is common, confers excess morbidity and mortality and contributes to duration of hospital stay and health economics.

\section{Current treatment options}

\section{Fluid restriction}

Water restriction is regarded as first-line treatment for hyponatraemia due to SIADH (in the majority of cases apart from patients with severe symptomatic hyponatraemia). It has been established for many years, and in patients in whom there is no question of hypovolaemia, this treatment is safe. Fluid restriction of $800-1200 \mathrm{ml} /$ day is generally advised, according to severity of hyponatraemia. As long as background water losses from the kidney, skin and lungs exceed this amount, there is progressive depletion of total body water and a gradual rise in plasma sodium concentration. The principal drawback is that patients find it extremely difficult to maintain fluid restriction, as thirst in SIADH is inappropriately normal due to a downward resetting of the osmotic thirst threshold (15). Hospitalised inpatients who can be supervised tend to do better with fluid restriction than outpatients, but even inpatients who are receiving fluid with i.v. cytotoxic agents or antibiotics, for instance, find it hard to comply. 
As a result, fluid restriction is often insufficient to reverse hyponatraemia, and is rarely quick enough to manage symptomatic hyponatraemia.

\section{Demeclocycline}

Demeclocycline is a tetracycline derivative which is utilised in the treatment of SIADH because it causes nephrogenic diabetes insipidus in about $60 \%$ of patients for whom it is prescribed. The mode of action is unknown, and the vasopressin resistance is not predictable; in a significant proportion of patients, it does not work. When it does work, the onset of action is also unpredictable, usually occurring after 2-5 days, but occasionally taking longer. In some patients, polyuria can be profound, and patients can become markedly symptomatic, occasionally developing hypernatraemia if access to water is compromised. Nephrotoxicity can arise, particularly in patients with cirrhosis, and although renal impairment is usually reversible with discontinuation, cases with permanent renal failure have been reported (16). It has also been associated with photosensitive skin rash, leading to discontinuation of treatment and return of symptomatic hyponatraemia.

\section{Lithium}

Lithium therapy also causes nephrogenic diabetes insipidus in $30 \%$ of patients (17), by downregulation of vasopressin-stimulated aquaporin-2 expression (18). An even larger proportion of patients have attenuation of maximal urine concentrating ability (19), and this property of lithium has been utilised by some centres to treat SIADH. The efficacy of lithium is unpredictable as not all patients develop nephrogenic diabetes insipidus, but it is the side effect profile which has caused sufficient concern that most physicians no longer consider it for treatment of SIADH. Nephrogenic diabetes insipidus is usually (20) but not always reversible (21), with chronic treatment sometimes producing interstitial nephritis (22) and end-stage renal failure (23). Additional side effects include hypothyroidism, tremor and rarely, hyperparathyroidism.

\section{Urea}

A relatively small number of centres have experience in the use of urea; it is unavailable in many countries, and the unpleasant taste has limited its use. Human studies have shown that long-term (5-year) treatment of hyponatraemia with urea is effective (24), and the same group has published data in a rat model of SIADH which suggests that treatment of hyponatraemia with urea may protect against brain complications such as myelinolysis $(25,26)$.

\section{Frusemide}

Frusemide was shown some years ago to be effective in the rapid correction of hyponatraemia in SIADH (27), but it is of limited efficacy in long-term treatment as the diuresis that it induces includes a natriuresis, which can occasionally worsen hyponatraemia.

\section{Saline infusion}

There is data to suggest that plasma sodium concentration will rise in some patients with SIADH who are treated with i.v. normal $(0.9 \%)$ saline, particularly if urine osmolality is $<530 \mathrm{mosmol} / \mathrm{kg}$ (28). However, treatment with normal saline is generally reserved for patients in whom the differentiation between hypovolaemia and euvolaemia is difficult; in this situation, i.v. saline is a safer first-line treatment than fluid restriction (as fluid restriction may exacerbate hypovolaemic hyponatraemia).

I.v. infusion of hypertonic saline, using either 3 or $5 \%$ saline strength, has been described, mainly for the correction of severe hyponatraemia, when patients are at risk of serious or life-threatening neurological sequelae. An expert panel published guidelines for the rate of i.v. infusion of hypertonic saline (29), and the Adrogue-Madias formula has also been used (30). The reason for the perceived need for formulae for infusion rates is the risk of central pontine (or extra pontine) myelinolysis with over-rapid correction of hyponatraemia. There is concern that the Adrogue-Madias equation, for instance, can lead to underestimation of the rate of rise of plasma sodium, and the patient must be carefully monitored with frequent measurement of plasma sodium concentration in order to make sure that the rate of infusion can be adjusted to prevent over-correction (31). A sensible approach is to start off on a fixed low dose infusion rate and adjust the rate of infusion on the basis of 2 hourly plasma sodium concentrations, in order to maintain a rate of rise of plasma sodium concentration of $<0.5 \mathrm{mmol} / \mathrm{l}$ per $\mathrm{h}$ or $12 \mathrm{mmol}$ over $24 \mathrm{~h}$. The maximum rate of rise of plasma sodium is adjusted down to $<8 \mathrm{mmol} / \mathrm{l}$, in $24 \mathrm{~h}$, in patient groups at greater risk of myelinolysis, such as alcoholics, malnourished individuals and slim young women. It remains to be proven that the vaptans will improve the predictability of the rise in serum sodium in patients with severe symptomatic hyponatraemia compared with patients treated with a well managed hypertonic saline infusion.

\section{Future treatment options: the vaptans}

It has been recognised for decades that plasma vasopressin concentrations are elevated in almost every case of SIADH (32). The availability, therefore, of specific antagonists to the vasopressin-2 receptor, the vaptans, has allowed clinicians to specifically target the pathophysiological cause of the disorder. Because the vaptans specifically prevent the reabsorption of water from the renal tubules, without affecting solute excretion, they have been termed aquaretics, to distinguish them from 
diuretics, which promote both water and solute excretion. They offer significant potential advantages over existing treatments for SIADH, which are unsatisfactory not just on the basis of lack of efficacy, side effect profile and lack of published evidence, but because they do not target the cause of SIADH.

Vasopressin exerts its antidiuretic effect by binding to the $\mathrm{V} 2$ receptors, which are situated in the basolateral surface of the cells of the collecting duct of the kidney. Receptor binding initiates an intracellular cascade which generates adenyl cyclase and an increase of intracellular cAMP. This causes protein synthesis, which leads to the production of mRNA for aquaporin-2, and insertion of pre-formed aquaporin into the apical membrane of the cell, allowing passage of free water across the cell, to be reabsorbed into the renal vasculature (33). The vaptans competitively bind to the V2 receptors, preventing vasopressin-mediated generation of aquaporin-2, thus causing a solute-free aquaresis. A number of $\mathrm{V} 2$ receptor antagonists have been studied in the treatment of SIADH, and the papers are documented in Table 2.

The interest in the potential use of vaptans has been heightened by the granting in 2009 of a licence by the European Medicines Agency for the use of tolvaptan specifically for the treatment of adult patients with hyponatraemia secondary to SIADH. Tolvaptan is an oral V2 receptor antagonist which has been shown in healthy individuals to have a greater aquaresis than either frusemide or hydrochlorothiazide, without having a significant natriuresis or kaliuresis (34). The effect of tolvaptan in SIADH was explored in the SALT-1 (conducted in US) and SALT-2 (conducted in US and Europe) trials (35). The patient groups in each study were heterogenous in the causation of hyponatraemia, in that they included individuals with hyponatraemia due to cardiac failure, liver failure and SIADH ( 40\%). The studies were designed as randomised, placebocontrolled trials of tolvaptan versus placebo; patients were not required to maintain fluid restriction. The tolvaptan dose was adjusted from 15 to $60 \mathrm{mg}$ daily according to clinical need, and was continued for 30 days, with patient monitoring continued for 7 days after discontinuation of tolvaptan.

Mean baseline serum sodium was similar in both the groups at $128 \mathrm{mmol} / \mathrm{l}$, but by day 4 the serum sodium concentration had risen more in the tolvaptan group

Table 2 V2 receptor antagonists in the treatment of SIADH.

\begin{tabular}{llll}
\hline Drug & $\begin{array}{l}\text { Receptor } \\
\text { action }\end{array}$ & $\begin{array}{l}\text { Mode of } \\
\text { administration }\end{array}$ & References \\
\hline Tolvaptan & V2 & Oral & $(35,40)$ \\
Conivaptan & V1a and V2 & I.v./oral & $(24,36,37,41,42)$ \\
Lixivaptan & V2 & Oral & $(43)$ \\
Mozavaptan & V2 & Oral & $(44)$ \\
Satavaptan & V2 & Oral & $(45)$ \\
\hline
\end{tabular}

V1 and V2, vasopressin receptors 1 and 2. than in the placebo group (to 134 vs $130 \mathrm{mmol} / \mathrm{l}$, $P<0.001)$. Serum sodium rose to a mean of $136 \mathrm{mmol} / \mathrm{l}$ in the tolvaptan group by the end of the study, but had not changed significantly in the placebo group. The greatest rise in serum sodium concentration was in those patients with the lowest baseline plasma sodium concentration. Side effects were predictable given the action of tolvaptan to increase water excretion, with thirst and dry mouth the most frequent. Serum sodium concentration rose at a greater rate than the maximum recommended rate of $0.5 \mathrm{mml} / \mathrm{l}$ per $\mathrm{h}$ in $<2 \%$ of cases. The results showed that tolvaptan had a predictable effect to increase free water clearance and cause an elevation in serum sodium concentration.

The patients in the SALT studies were not subdivided into separate aetiological subgroups, so that the effects specifically in SIADH patients could not be discerned from the group as a whole (35). In addition, because the mean baseline plasma sodium concentrations $(128 \mathrm{mmol} / \mathrm{l})$ reflected a population with moderate hyponatraemia, it is not possible to comment on the effect of tolvaptan in those patients with severe hyponatraemia, in whom significant elevation of plasma sodium concentrations could lead to complication such as myelinolysis. This is particularly an important consideration, given the observation that the greatest rise in plasma sodium occurred in those patients with the lowest baseline concentrations. Further work is necessary to determine whether the rate of rise of plasma sodium concentration in patients with severe hyponatraemia is sufficiently predictable and controllable to allow tolvaptan to replace hypertonic saline in this situation. However, the data would indicate that tolvaptan has an acceptable safety profile, and is predictable in the treatment of mild to moderate hyponatraemia due to SIADH. Data from the SF-12 Mental Component Score readings in the study showed that the mean score improved in the tolvaptan group from readings comparable to those derived from patients with depression, close to the normal adult mean at the end of treatment, indicating that the rise in plasma sodium concentration observed during the study was symptomatically beneficial.

Verbalis (36) published data from a subgroup analysis of patients with euvolaemic hyponatraemia treated with either i.v. conivaptan or placebo. Although patients who needed emergency treatment with hypertonic saline were excluded from the study, patients with plasma sodium concentrations as low as $115 \mathrm{mmol} / \mathrm{l}$ were included in the protocol. The results of this study were similar to those for tolvaptan, with conivaptan causing significant elevations in plasma sodium concentration compared with placebo, with little in the way of serious adverse events; infusion reactions were the commonest side effect. This study, conducted in a population of predominantly SIADH patients, confirmed the important role that the vaptans are likely to play in the treatment of this condition. 
The most likely role for vaptans in the immediate future is in the treatment of mild to moderate hyponatraemia due to SIADH. Because there is a paucity of data in symptomatic severe hyponatraemia, hypertonic saline is likely to remain the treatment of choice in this group until more data are available to the clinician. Although mild hyponatraemia has traditionally been treated with water restriction as first-line therapy, the difficulty with patient compliance in SIADH, due to the downward resetting of the thirst threshold (15), means that the vaptans are likely to replace water restriction as first-line treatment. The fact that both tolvaptan (35) and conivaptan (currently only licensed in the USA) (37) are effective without the need for fluid restriction means that patient acceptability will be superior to that of water restriction. The extent to which vaptans replace fluid restriction as first-line therapy may be predicated upon appropriate pricing of the drug to allow it to be accommodated in hard pressed therapeutic budgets. An important determinant of competitive pricing may be the potential for treatment of hyponatraemia to negate the extra financial burden associated with the condition. A number of studies have documented increased duration of hospital stay $(6,38)$ and intensive care stay $(4,38)$, in patients with hyponatraemia due to disparate causes. One of these studies calculated that hyponatraemia in pneumonia patients was associated with an excess of $\$ 1300$ to total hospital costs (this was a study based in the USA and cost implications in other medical systems may be different) (38). Analysis of data from the Integrated Health Care Information Services National Managed Care Benchmark Database in the United States calculated that hyponatraemia was a predictor on cumulative medical costs at 6 months ( $41 \%$ increase) and 12 months (46\%) after discharge from hospital (39). At present, the data are not available; however, if it can be shown that treatment of SIADH can ameliorate some of the financial burden associated with hyponatraemia, the current relatively high unit costs of the vaptans may make fiscal sense to health care providers.

Tolvaptan has specifically been licenced in Europe for the treatment of euvolaemic hyponatraemia, and it is specifically, and correctly, not recommended for hypovolaemic hyponatraemia. Because the aquaresis generated by tolvaptan will further reduce extracellular fluid volume, treatment of hypovolaemic hyponatraemia with this drug would worsen the clinical situation. Although it is not always easy to differentiate between euvolaemia and mild hypovolaemia, this is a challenge which must be considered by the prescribing physician; in cases of diagnostic doubt, a careful $0.9 \%$ saline challenge may be the safest first step. Patients with hypovolaemic hyponatraemia are likely to respond well to i.v. $0.9 \%$ saline, with a significant rise in plasma sodium and a fall in blood urea; patients with SIADH are likely to have a modest response, if any.
SIADH complicates $\sim 30 \%$ of patients with subarachnoid haemorrhage (6). Data on the response of SIADH due to subarachnoid haemorrhage to treatment with vaptans have not been published to date. Neurosurgeons are keen to avoid hypovolaemia and the potential for cerebral vasospasm, so treatment of this group of patients should probably wait for careful, controlled studies.

\section{Conclusions}

Hyponatraemia is the commonest electrolyte abnormality, and SIADH is the most frequent underlying pathophysiology. Hyponatraemia is associated with significant morbidity and mortality, and as such appropriate treatment is essential. Treatment options for SIADH include fluid restriction, demeclocycline, urea, frusemide and saline infusion, all of which have their limitations. The introduction of the vasopressin-2 receptor antagonists has allowed clinicians to specifically target the underlying pathophysiology of SIADH. Initial studies have shown good efficacy and safety profiles in the treatment of mild to moderate hyponatraemia. However, studies assessing the efficacy and safety of these agents in acute severe symptomatic hyponatraemia are awaited. Furthermore, the cost of these agents at present may limit their use.

\section{Declaration of interest}

C J Thompson is on the advisory board of Otsuka Pharmaceuticals, and has received research funding from Novo Nordisk, Servier and Pfizer Pharmaceuticals. M Sherlock is a MRC Research Training Fellow, and reports no conflicts of interest. This paper forms part of a European Journal of Endocrinology supplement, supported by Otsuka Pharmaceutical Europe Ltd. The opinions or views expressed in this supplement are those of the authors, and do not necessarily reflect the opinions or recommendations of Otsuka Pharmaceutical Europe Ltd.

\section{References}

1 Verbalis J. Hyponatraemia Water and Salt Homeostasis in Health and Disease. edn 1, pp. 499-530, London: Baillière Tindall, 1989.

2 Gill G, Huda B, Boyd A, Skagen K, Wile D, Watson I \& van Heyningen C. Characteristics and mortality of severe hyponatraemia - a hospital-based study. Clinical Endocrinology $200665246-249$.

3 Sajadieh A, Binici Z, Mouridsen MR, Nielsen OW, Hansen JF \& Haugaard SB. Mild hyponatremia carries a poor prognosis in community subjects. American Journal of Medicine 2009122 679-686.

4 Stelfox HT, Ahmed SB, Khandwala F, Zygun D, Shahpori R \& Laupland K. The epidemiology of intensive care unit-acquired hyponatraemia and hypernatraemia in medical-surgical intensive care units. Critical Care 200812 R162.

5 Waikar SS, Mount DB \& Curhan GC. Mortality after hospitalization with mild, moderate, and severe hyponatremia. American Journal of Medicine 2009122 857-865.

6 Sherlock M, O’Sullivan E, Agha A, Behan LA, Rawluk D, Brennan P, Tormey $\mathrm{W} \&$ Thompson CJ. The incidence and pathophysiology of hyponatraemia after subarachnoid haemorrhage. Clinical Endocrinology $200664250-254$. 
7 Arieff AI, Llach F \& Massry SG. Neurological manifestations and morbidity of hyponatremia: correlation with brain water and electrolytes. Medicine 197655 121-129.

8 Renneboog B, Musch W, Vandemergel X, Manto MU \& Decaux G. Mild chronic hyponatremia is associated with falls, unsteadiness, and attention deficits. American Journal of Medicine 2006119 71-78.

9 Gankam KF, Andres C, Sattar L, Melot C \& Decaux G. Mild hyponatremia and risk of fracture in the ambulatory elderly. Quarterly Journal of Medicine 2008101 583-588.

10 Smith DM, McKenna K \& Thompson CJ. Hyponatraemia. Clinical Endocrinology $2000 \mathbf{5 2} 667-678$.

11 Clayton JA, Le Jeune IR \& Hall IP. Severe hyponatraemia in medical in-patients: aetiology, assessment and outcome. Quarterly Journal of Medicine 200699 505-511.

12 Hoorn EJ, Lindemans J \& Zietse R. Development of severe hyponatraemia in hospitalized patients: treatment-related risk factors and inadequate management. Nephrology, Dialysis, Transplantation 200621 70-76.

13 Chow KM, Kwan BC \& Szeto CC. Clinical studies of thiazideinduced hyponatremia. Journal of the National Medical Association 200496 1305-1308.

14 Verbalis JG, Barsony J, Sugimura Y, Tian Y, Adams DJ, Carter EA \& Resnick HE. Hyponatremia-induced osteoporosis. Journal of Bone and Mineral Research 2009. In press. DOI:10.1359/jbmr.090827.

15 Smith D, Moore K, Tormey W, Baylis PH \& Thompson CJ. Downward resetting of the osmotic threshold for thirst in patients with SIADH. American Journal of Physiology. Endocrinology and Metabolism 2004287 E1019-E1023.

16 Carrilho F, Bosch J, Arroyo V, Mas A, Viver J \& Rodes J. Renal failure associated with demeclocycline in cirrhosis. Annals of Internal Medicine 197787 195-197.

17 Baylis PH \& Heath DA. Water disturbances in patients treated with oral lithium carbonate. Annals of Internal Medicine $1978 \mathbf{8 8}$ 607-609.

18 Nielsen J, Hoffert JD, Knepper MA, Agre P, Nielsen S \& Fenton RA. Proteomic analysis of lithium-induced nephrogenic diabetes insipidus: mechanisms for aquaporin 2 down-regulation and cellular proliferation. PNAS $2008 \mathbf{1 0 5} 3634-3639$.

19 Waller DG, Edwards JG \& Papasthatis-Papayanni S. A longitudinal assessment of renal function during treatment with lithium. Quarterly Journal of Medicine 198868 553-558.

20 Lindop GB \& Padfield PL. The renal pathology in a case of lithiuminduced diabetes insipidus. Journal of Clinical Pathology $1975 \mathbf{2 8}$ 472-475.

21 Thompson CJ, Freeman J, Record CO \& Baylis PH. Hypernatraemia due to a reset osmostat for vasopressin release and thirst, complicated by nephrogenic diabetes insipidus. Postgraduate Medical Journal 198763 979-982.

22 Walker RG, Escott M, Birchall I, Dowling JP \& Kincaid-Smith P. Chronic progressive renal lesions induced by lithium. Kidney International $198629875-881$.

23 Grunfeld JP \& Rossier BC. Lithium nephrotoxicity revisited. Nature Reviews. Nephrology 20095 270-276.

24 Decaux G. Long-term treatment of patients with inappropriate secretion of antidiuretic hormone by the vasopressin receptor antagonist conivaptan, urea, or furosemide. American Journal of Medicine $2001110582-584$.

25 Soupart A, Schroeder B \& Decaux G. Treatment of hyponatraemia by urea decreases risks of brain complications in rats. Brain osmolyte contents analysis. Nephrology, Dialysis, Transplantation 200722 1856-1863.

26 Van Reeth $\mathrm{O} \&$ Decaux G. Rapid correction of hyponatraemia with urea may protect against brain damage in rats. Clinical Science 198977 351-355.

27 Hantman D, Rossier B, Zohlman R \& Schrier R. Rapid correction of hyponatremia in the syndrome of inappropriate secretion of antidiuretic hormone. An alternative treatment to hypertonic saline. Annals of Internal Medicine $1973 \mathbf{7 8} 870-875$.

28 Musch W \& Decaux G. Treating the syndrome of inappropriate $\mathrm{ADH}$ secretion with isotonic saline. Ouarterly Journal of Medicine $199891749-753$
29 Verbalis JG, Goldsmith SR, Greenberg A, Schrier RW \& Sterns RH. Hyponatremia treatment guidelines 2007: expert panel recommendations. American Journal of Medicine 2007120 S1-S21.

30 Adrogue HJ \& Madias NE. Hyponatremia. New England Journal of Medicine 2000342 1581-1589.

31 Mohmand HK, Issa D, Ahmad Z, Cappuccio JD, Kouides RW \& Sterns RH. Hypertonic saline for hyponatremia: risk of inadvertent overcorrection. Clinical Journal of the American Society of Nephrology 20072 1110-1117.

32 Robertson GL, Aycinena P \& Zerbe RL. Neurogenic disorders of osmoregulation. American Journal of Medicine 198272 339-353.

33 Lien YH \& Shapiro JI. Hyponatremia: clinical diagnosis and management. American Journal of Medicine 2007120 653-658.

34 Shoaf SE, Bramer SL, Bricmont P \& Zimmer CA. Pharmacokinetic and pharmacodynamic interaction between tolvaptan, a nonpeptide AVP antagonist, and furosemide or hydrochlorothiazide. Journal of Cardiovascular Pharmacology 200750 213-222.

35 Schrier RW, Gross P, Gheorghiade M, Berl T, Verbalis JG, Czerwiec FS \& Orlandi C. Tolvaptan, a selective oral vasopressin V2-receptor antagonist, for hyponatremia. New England Journal of Medicine $20063552099-2112$.

36 Verbalis JG, Zeltser D, Smith N, Barve A \& Andoh M. Assessment of the efficacy and safety of intravenous conivaptan in patients with euvolaemic hyponatraemia: subgroup analysis of a randomized, controlled study. Clinical Endocrinology 200869 159-168.

37 Annane D, Decaux G \& Smith N. Efficacy and safety of oral conivaptan, a vasopressin-receptor antagonist, evaluated in a randomized, controlled trial in patients with euvolemic or hypervolemic hyponatremia. American Journal of the Medical Sciences $200933728-36$.

38 Zilberberg MD, Exuzides A, Spalding J, Foreman A, Jones AG, Colby $\mathrm{C} \&$ Shorr AF. Hyponatremia and hospital outcomes among patients with pneumonia: a retrospective cohort study. BMC Pulmonary Medicine $2008 \mathbf{8} 16$.

39 Shea AM, Hammill BG, Curtis LH, Szczech LA \& Schulman KA. Medical costs of abnormal serum sodium levels. Journal of the American Society of Nephrology 200819 764-770.

40 Madias NE. Effects of tolvaptan, an oral vasopressin V2 receptor antagonist, in hyponatremia. American Journal of Kidney Diseases 200750 184-187.

41 Ghali JK, Koren MJ, Taylor JR, Brooks-Asplund E, Fan K, Long WA \& Smith N. Efficacy and safety of oral conivaptan: a V1A/V2 vasopressin receptor antagonist, assessed in a randomized, placebo-controlled trial in patients with euvolemic or hypervolemic hyponatremia. Journal of Clinical Endocrinology and Metabolism $2006912145-2152$.

42 Zeltser D, Rosansky S, van Rensburg H, Verbalis JG \& Smith N. Assessment of the efficacy and safety of intravenous conivaptan in euvolemic and hypervolemic hyponatremia. American Journal of Nephrology 200727 447-457.

43 Wong F, Blei AT, Blendis LM \& Thuluvath PJ. A vasopressin receptor antagonist (VPA-985) improves serum sodium concentration in patients with hyponatremia: a multicenter, randomized, placebo-controlled trial. Hepatology 200337 182-191.

44 Saito T, Ishikawa S, Abe K, Kamoi K, Yamada K, Shimizu K, Saruta T \& Yoshida S. Acute aquaresis by the nonpeptide arginine vasopressin (AVP) antagonist OPC-31260 improves hyponatremia in patients with syndrome of inappropriate secretion of antidiuretic hormone (SIADH). Journal of Clinical Endocrinology and Metabolism 199782 1054-1057.

45 Soupart A, Gross P, Legros JJ, Alfoldi S, Annane D, Heshmati HM \& Decaux G. Successful long-term treatment of hyponatremia in syndrome of inappropriate antidiuretic hormone secretion with satavaptan (SR121463B), an orally active nonpeptide vasopressin V2-receptor antagonist. Clinical Journal of the American Society of Nephrology 20061 1154-1160.

Received 15 February 2010

Accepted 16 February 2010 